\title{
PENDAMPINGAN PROGRAM PEMBERDAYAAN MASYARAKAT MELALUI PELAYANAN SOSIAL DAN PENDIDIKAN DI MASJID AGUNG BANGIL
}

\author{
Siti Yumnah \\ STAI Pancawahana Bangil, Indonesia \\ sitiyumnah30@gmail.com
}

\begin{abstract}
Community empowerment is one of the important activities that needs to be carried out to empower, especially mosque-based community empowerment. The community service method used is mosque-based management, which aims to find out mosque-based community empowerment for social and educational services at the Great Mosque of Bangil by conducting previous observations and collecting data and interviews with parties involved in community empowerment at the Great Mosque Bangil. And the results of the research got are that community empowerment at the Great Bangil Mosque can foster and educate the community and children through mosque committee programs developed through the social and educational fields.
\end{abstract}

Keywords: Community Empowerment Program, Social Services and Education, Great Mosque of Bangil Masjid 


\section{Pendahuluan}

Islam dan pengikutnya secara teratur beribadah. Jika beribadah dilakukan dengan ikhlas dan mengikuti ajaran Rasulullah SAW, maka akan merasa lebih baik. Di antara ibadah wajib yang dikerjakan oleh umat Islam setiap waktu yaitu ibadah shalat fardhu. Sholat fadu di masjid lebih banyak pahala dan lebih utama karena dikerjakan secara bersama. $^{1}$

Masjid bukan hanya tempat ibadah, tetapi harus ditafsirkan di semua tingkatan kehidupan. Antara lain sebagai usaha pemberdayaan masyarakat dan peningkatan perekonomian masyarakat, seperti pengelola baitul mal, BAZNAS, pengelola infaq dan shodaqah. Maka dari itu, dalam memanajemen masjid harus diakui jika masjid digunakan sebaik-baiknya maka masjid memiliki potensi yang besar bagi masyarakat, dan akan meningkatkan kesejahteraan masyarakat, setidaknya untuk silaturahmi umat itu sendiri. ${ }^{2}$

Dari masa ke masa peran masjid sangat strategis dalam masyarakat Islam. Selain berfungsi sebagai tempat melakukan ritual

${ }^{1}$ Moh. Roqib, Menggugat Fungsi Edukasi Masjid, (Yogyakarta: Grafindo Litera Media, 2005), hlm. 71.

2 Said Agil Husein Al Munawar, Sambutan Menteri Agama Republik Indonesia, Dalam Buku Pedoman Manajemen Masjid, hlm. 35.

Vol. 3 No.2, Oktober 2021

Siti Yumnah | 320 gurnal Pengabdian Masyarakat 
ibadah, masjid juga memiliki fungsi sebagai wadah pembangunan umat secara menyeluruh. Tujuan Rasulullah SAW mendirikan masjid pertamanya di Madinah adalah dengan tujuan untuk mencerahkan umat dan memperkenalkan pesan-pesan suci. Masjid tidak hanya digunakan untuk salat berjamaah, dzikir, membaca Al-Qur'an dan salat dan kegiatan ibadah ritual lainnya, tetapi juga dapat digunakan sebagai tempat menyelenggarakan kegiatan sosial keagamaan untuk mengembangkan kepekaan sosial masyarakat terhadap ajaran Islam. Bahkan hingga ini eksistensi masjid memiliki potensi yang besar, terutama dalam pemberdayaan umat Islam dalam segala aspek kehidupan. Dengan munculnya slogan back to masjid menjadi awal motivasi bagi tumbuhnya semangat mengembalikan kejayaan Islam melalui masjid. ${ }^{3}$

Memakmurkan masjid merupakan kewajiban semua umat Islam, sehingga kita harus bisa mengelola supaya masjid benar-benar dapat menjalankan perannya sebagaimana mestinya. Sebagai umat Islam, kita memiliki misi untuk memakmurkan masjid, maka dari itu kita perlu memiliki pengetahuan tentang manajemen masjid untuk menertibkan

3 Ade Ridwan Iwanullah \& Dedi Herdiana, “Optimalisasi Pemberdayaan Masyarakat Berbasis Masjid”, Jurnal Ilmu Dakwah Volume 12 Nomor 1 (2018), hlm. 83

Vol. 3 No.2, Oktober 2021

Siti Yumnah | 321 gurnal Pengabdian Masyarakat 
aktivitas di dalam masjid, bukan hanya sebagai simbol kejayaan. ${ }^{4}$

Namun seiring berjalannya waktu, masjid kini secara perlahan mulai ditinggalkan oleh para pemeluknya, selain untuk kebutuhan beribadah. Masjid saat ini hanya digunakan sebagai tempat sholat, pengajian dan kegiatan keagamaan. Hal tersebut terlihat pada masjidmasjid agung di tingkat kabupaten/kota saat ini. Meskipun harus diakui bahwa sebagian umat Islam telah melakukan upaya tidak hanya untuk menggunakan masjid sebagai sarana ibadah, melainkan digunakan juga sebagai sarana beragam kegiatan umat Islam lainnya, seperti melakukan kegiatan sosial, pendidikan, dan kegiatan lainnya, akan tetapi berbagai usaha tersebut nyatanya belum banyak dilaksanakan. ${ }^{5}$

Untuk menjaga kelestarian dan pengembangkan masjid, dibutuhkan sebuah ide dan konsep yang sangat inovatif, serta keinginan dari semua pihak yang terlibat, terutama pengelola masjid. Seperti Masjid Agung Bangil, banyak kegiatan yang telah dilakukan, misalnya mulai pukul 15.30-17.00, anak-anak dari SD hingga SMP akan mengaji

4 Rohman dkk, "Program Pemberdayaan Masyarakat Berbasis Masjid", Journal Lifelog Learning Vol. 3 No.2. 124-130(November 2020), hlm. 3

5 Tajuddin Hajma,"Manajemen Kemasjidan”. Makalah yang disajikan selama proses perkuliahan berlangsung di Universitas Islam Negeri Alauddin Makassar, Kampus II Samata-Gowa 2016, hlm. 168

Vol. 3 No.2, Oktober 2021

Siti Yumnah | 322 gurnal Pengabdian Masyarakat 
setiap hari, dan mengikuti kajian kitab bersama Kyai dan Habaib setelah sholat Maghrib hingga selesai menjelang sholat isya'. Kemudian Tadarus Al-Qur'an dan membaca Maulid Diba' dilaksanakan setiap Rabu malam dan setiap Sabtu malam. Semua ini untuk membuat masyarakat setempat berduyun-duyun ke masjid untuk berpartisipasi dalam kegiatan tersebut. Tidak hanya saat beribadah, masyarakat juga bisa datang ke masjid. Oleh karena itu, jamaah Masjid Agung Bangil tidak pernah berhenti datang ke masjid untuk mengikuti kegiatan tersebut.

Saat ini dalam mengelola masjid harus membutuhkan pengetahuan dan keterampilan. Seorang Ta'mir masjid harus mampu beradaptasi dengan perkembangan jaman yang selalu berubah. Di bawah pengelolaan masjid yang masih menggunakan sistem tradisional, sulit bagi umat Islam untuk berkembang. Faktanya, masjid tidak akan maju, tetapi malah tersingkir, dan semakin ketinggalan zaman. Masjid akan mengalami stagnansi, jika tidak dikelola dengan baik, dan akhirnya akan ditinggalkan jamaahnya. Ta'mir masjid harus bekerja sama dengan baik dalam mengatur roda pengelolaan, dan perlu mengaplikasikan pengelolaan dan mekanisme kerja masjid yang baik. Melalui pengelolaan yang baik, dengan sistem modern dan profesional, 
maka pemberdayaan masjid dapat terlaksana secara maksimal. ${ }^{6}$

\section{Metode}

Dalam penelitian ini, penulis menggunakan beberapa metode dalam penelitian pengabdian masyarakat ini, antara lain:

\section{Pendekatan Manajemen}

Pada dasarnya, kemampuan manusia yang meliputi (tubuh, pengetahuan, waktu, dan perhatian) sangatlah terbatas, sedangkan kebutuhannya tidak terbatas. Upaya pemenuhan kebutuhan dan keterbatasan kemampuan kerja mendorong orang untuk membagi pekerjaan, tugas, dan tanggung jawab. Melalui pembagian kerja, tugas dan tanggung jawab ini, maka kerjasama formal dan partisipasi dalam organisasi terbentuk. Dalam organisasi ini, pekerjaan yang berat dan sulit akan diselesaikan dengan baik untuk mencapai tujuan yang diharapkan. ${ }^{7}$

\section{Pendekatan Sosiologi}

Pendekatan sosiologi merupakan teknik untuk mengkaji struktur

${ }^{6}$ Ibid, hlm. 120

7 Malayu Hasibuan, Manajemen: Dasar, Pengertian, dan Masalah, (Ed. Revisi, Cet. 6 Jakarta: Bumi Aksara, 2007), hlm. 3.

Vol. 3 No.2, Oktober 2021

Siti Yumnah | 324 Zurnal Pengabdian Masyarakat 
sosial dan siklus sosial, termasuk di antaranya mengenai perubahan sosial. Struktur sosial yang dimaksud adalah keseluruhan struktur komponen sosial utama, yakni norma-norma sosial, sistem sosial, kelompok dan tingkatan sosial. Pendekatan sosial adalah saling mempengaruhi antara semua aspek kehidupan bersama dan semua aspek kehidupan beragama, semua aspek kehidupan hukum dan semua aspek kehidupan ekonomi, dan sebagainya.

Sementara itu, untuk memperoleh sumber data dalam penelitian, penulis menggunakan dua sumber data, yaitu sumber data primer dan sumber data sekunder.

Pertama,Sumber data primer adalah data yang diambil langsung oleh peneliti melalui hasil observasi dan wawancara dengan subjek penelitian/informan. Sumber data primer biasanya berupa catatan tertulis atau berupa hasil rekaman kaset video/audio, foto atau film. Dalam penelitian ini, objek yang diamati adalah segala sesuatu yang berhubungan dengan masjid dan tokoh masyarakat yang ikut serta dalam pelayanan sosial Masjid Agung Bangil. Pada saat yang sama, yang diwawancarai akan menjadi orang utama yang memahami konsep pelayanan sosial Masjid Agung Bangil. Adapun tokoh-tokoh tersebut 
adalah:

a. Ketua takmir Masjid Agung Bangil.

b. Ketua seksi bidang di kepengurusan takmir masjid.

c. Tokoh masyarakat setempat, dan

d. Jama'ah Masjid Agung Bangil.

Kedua, data sekunder, merupakan sumber data kedua setelah data primer, atau yang biasanya disebut sebagai data tambahan yang diperoleh dari pihak lain. Sumber data sekunder ini berupa dokumen tertulis, antara lain buku-buku pengetahuan populer, laporan hasil penelitian, data statistik, arsip penting, dokumen pribadi, dokumen resmi, dan semua buku atau catatan tertulis yang berkaitan dengan topik penelitian. Data tersebut dipergunakan untuk memperkaya sumber data guna untuk memperkuat analisis dan kesimpulan penelitian, yang tersedia melalui internet, buku-buku dan Takmir Masjid.

\section{Hasil dan Diskusi}

\section{Gambaran Umum Masjid Agung Bangil}

Letak geografis Masjid Agung Bangil, terletak di Jl. Alun-alun Barat No. 66 A, Kauman, Bangil, Pasuruan, Jawa Timur. Bangunan 
masjid ini megah, keberadaan masjid ini berada persis di sebelah barat Alun-Alun Bangil. Konon menurut cerita masyarakat setempat, bangunan masjid ini merupakan masjid tiban (tiba-tiba muncul), dalam arti, bangunan yang terbuat kayu ini tiba-tiba muncul di tengah Kota Bangil. Seorang kyai menjelaskan bahwa masjid tersebut tidak muncul secara tiba-tiba, tetapi dibangun dengan sengaja oleh seorang yang alim dengan bantuan para pengikutnya, tidak ada masyarakat sekitar yang mengetahui proses pembangunan masjid tersebut.

Masjid Raya Bangil memiliki 16 pengurus, 4 imam dan 12 Khatib. Masjid ini dibangun pada tahun $1278 \mathrm{M}$, terbukti dari data yang tertera pada artefak Mihrob. Bangunan masjid ini terletak di atas sebidang tanah dengan memiliki luas sebesar 2.500 meter persegi, dan status tanahnya adalah tanah wakaf. Luas bangunan masjid adalah 2000 meter persegi. Bisa menampung 5.000 jemaah haji. Masjid Agung Bangir merupakan bangunan masjid yang terbuat dari bahan kayu jati, memiliki 4 tiang utama yang disebut SOKO WOLU. Setiap tiang memiliki keliling $120 \mathrm{~cm}$ dan tinggi 15 meter. Delapan balok kayu jati, panjang $120 \mathrm{~cm}$ dan panjang 7 meter, dipaku ke karung dan dipaku satu sama lain. Kini ruang utama masjid telah direnovasi, namun tetap 
mempertahankan cita rasa asli arsitektur masjid tanpa kehilangan tampilan aslinya.

Kegiatan di kompleks Masjid Agung Bangil sudah begitu kompleks karena kegiatan di sini melibatkan semua kelompok umur dan semua jenis kelamin. Wilayah yang dicakup juga cukup besar yaitu: peribadatan, pendidikan agama dan umum, sosial keagamaan, dan lainlain, sehingga mendorong manajemen untuk mengupayakan sarana dan prasarana yang memadai. Adapun kegiatan peribadatan yakni:

1. Kegiatan peribadatan: penyelenggaraan shalat Jumat, penyelenggaraan shalat Fardhu, penyelenggaraan Dakwah, pengajian secara rutin,

2. Pendidikan masyarakat meliputi: Madrasah, pusat kegiatan belajar masyarakat,

3. Pendidikan agama meliputi: TPA

4. Sosial dan Agama: Pemberdayaan Zakat, Pemberdayaan Infaq, Pemberdayaan Shodaqoh dan Wakaf.

Selain itu masih terdapat kepanitiaan yang bersifat temporer seperti:

1. Menyelenggarakan Kegiatan Hari Besar Islam, 
2. Menyelenggarakan /Tabliq Akbar.

\section{Pemberdayaan Masjid Bidang Sosial}

Untuk meningkatkan mutu pelatihan bagi umat Islam, Masjid Agung Bangil menawarkan berbagai jenis pelayanan untuk membantu kebutuhan keagamaan, termasuk di antaranya:

a. Melayani penyelenggaraan jenazah bagi warga yang meninggal dunia dan ta'ziah.

Masjid Agung Bangil memberikan pelayanan gratis kepada anggota masyarakat yang kerabat atau anggota keluarganya telah meninggal dunia, mulai dari memandikan jenazah hingga pemakamannya, serta ta'ziah bagi warga Muslim yang kurang mampu, masjid yang membantu memenuhi kebutuhan mereka. Karena Masjid Agung Bangil sudah dipersiapkan sejak awal, kecuali pejabat yang bertanggung jawab mengorganisir jenazah, maka warga Kecamatan Bangil harus melapor ke masjid setiap kali ada yang meninggal, agar bisa memberi tahu warga seluruh masyarakat atau kerabat kita yang meninggal dunia. Oleh karena itu, Masjid Agung Bangil hanya dapat membantu orang yang berduka dengan apa yang mereka butuhkan, dan bukan berarti membayar semua kebutuhan mereka. 
b. Sunatan Massal

Masjid Agung Bangil dan Puskesmas Bangil menyelenggarakan acara sunatan massal. Masjid Agung Bangil dapat bekerjasama dengan Puskesmas Bangil, menyediakan sarana dan prasarana yang dibutuhkan serta para donatur yang membayar penuh untuk obatobatan yang dibutuhkan untuk sunatan massal tersebut. Oleh karena itu, hanya masjid yang menyediakan ruang dan merekrut anak-anak yang ingin disunat atau yang membutuhkan bantuan tersebut. Melalui kegiatan tersebut, masjid mendapat banyak manfaat bagi masyarakat. ${ }^{8}$

c. Menggerakkan anggota dan masyarakat untuk ikut serta dalam setiap kegiatan di masjid.

Menurut penuturan Bapak Nur Syamsi selaku jamaah Masjid Agung Bangil mengatakan bahwa jika kita tidak mengajak orang-orang untuk datang ke masjid, maka akan muncul asumsi masyarakat dengan alasan mereka tidak mau datang ke masjid karena mereka menganggap orang yang datang ke masjid hanyalah untuk para pengurus yang terlibat dalam pengelolaan kegiatan masjid. Oleh

8 Wawancara dengan ketua ta'mir masjid agung bangil

Vol. 3 No.2, Oktober 2021

Siti Yumnah | 330 gurnal Pengabdian Masyarakat 
karenanya, kita harus saling memanggil atau mengajak semua tetangga biar setiap ada acara bisa menyempatkan diri untuk datang ke masjid dan membuka hati agar selalu pergi ke masjid, di sisi lain kita juga mendapatkan berkah dan ilmu tambahan. Karena diajak, belum tentu mau datang ke masjid, apalagi kalau tidak diajak.

d. Mengkoordinasi penjengukan anggota yang sedang sakit.

Seluruh pengurus masjid harus bisa meluangkan waktu dan membimbing anggota untuk menjenguk sanak saudara yang terdampak musibah, terlepas dari perawatan di rumah sakit atau tidak, karena menjenguk orang yang sakit terdapat keutamaan dan manfaat yang luar biasa, termasuk diantaranya:

1) Dapat memberinya perasaan dan kesan bahwa ia diperhatikan dan dicintai oleh orang-orang di sekitarnya, dan ia diharapkan agar cepat sembuh dari penyakitnya. Ini dapat membantu meyakinkan hati orang yang sakit.

2) Dapat menumbuhkan semangat, motivasi dan nasehat bagi kerabat/tetangga yang sedang sakit, dan dapat menjadi penguat dalam jiwanya untuk melawan rasa sakit yang dideritanya. 
Dengan mencari tahu apa yang dia butuhkan, belajar dari penderitaan yang dia alami, dan berdoa untuknya.

e. Menyediakan atau melaksanakan pemotongan dan pembagian hewan kurban.

Menjelang Hari Raya Idul Fitri, warga Bangil dan sekitarnya yang hendak berqurban, mereka akan membentuk qurban bagi siapa saja yang tiap kelompoknya terdiri dari 7 orang untuk menyembelih 1 ekor sapi. Oleh karena itu, bagi yang ingin berqurban di masjid dihimbau untuk segera mendaftarkan namanya sebelum menjelang Hari Raya Idul Adha, karena selain dapat mengurangi beban ekonomi masyarakat yang ekonominya sedang terpuruk juga dapat menjangkau masyarakat untuk rela berqurban.

Dengan melakukan kegiatan berqurban, masyarakat dapat belajar untuk berbagi dengan tulus kepada orang percaya lainnya, terutama bagi mereka yang tidak beruntung. Dengan berkurban ini, orangorang miskin pun merasakan betapa indahnya Islam di hari raya kurban.

f. Menjemput sumbangan dari para jama' ah setiap Bulan Ramadhan.

Setiap bulan Ramadhan, Masjid Agung Bangil akan menerima donasi 
dari jamaah berupa donasi konsumsi maupun non konsumsi dari donatur tetap. Hal tersebut sangat bermanfaat guna menambah semangat mereka dan berduyun-duyun ke masjid untuk melaksanakan shalat berjamaah, khususnya shalat Tarawih.

g. Pengadaan mobil jenazah.

Mobil jenazah yang dipersiapkan oleh Masjid Agung Bangil, merupakan mobil yang disediakan oleh jamaah atau bantuan donatur tetap, dan dapat digunakan oleh seluruh warga Kecamatan Bangil dan sekitarnya. Jika ada yang membutuhkan, panitia dapat menyiapkan mobil untuk keperluan jenazah, jika pihak keluarga yang terkena musibah merasa tidak mampu, maka pihak pengelola mobil jenazah akan membebaskan tanggungan biaya seluruh anggota keluarga untuk menggunakan ambulan dan melampirkan sertifikat RT dan RW untuk persyaratan administrasi manajemen.

\section{Pemberdayaan Masjid Bidang Pendidikan}

a. Membina Taman Pendidikan al-Qur'an (TPA) anak-anak dan dewasa.

Keadaan Siswa TPA di Masjid Agung Bangil Menurut data pada April 2020 lalu, jumlah siswanya adalah 40 siswa, yang dimulai dari 
tingkat i'dad sampai ke kelas 4. Adapun jumlah ustadznya sebanyak 7 orang dan jumlah ustadzahnya sebanyak 2 orang. Pada tahun 2021, jumlah siswa meningkat lagi menjadi 50. Setiap tahun pada bulan Juni, diadakan wisuda. Dan jumlah siswa yang mengikuti acara wisuda terbagi dua waktu karena masih dalam kondisi pandemi covid-19, dengan kloter pertama sebanyak 20 siswa, Jadi jumlah siswa yang tersisa untuk bulan Agustus adalah 20. Pengelola TPA Masjid Agung Bangil tidak ada batasan usia bagi anak-anak yang ingin belajar di TPA, dan pengelola akan menerimanya kapan saja. Waktu belajarnya dimulai pada jam 15.30-17.00 atau dimulai ba'da Asar sampai menjelang Maghrib, kurang lebih 90 menit dalam setiap pertemuan. Pembelajaran dilakukan 6 kali pertemuan dalam seminggu (libur pada hari Minggu). Berikut beberapa materi yang diajarkan di TPA Masjid Agung Bangil:

1). Metode Iqra' bagi yang baru permulaan belajar huruf Arab.

2). Tadarrus Al-Qur'an.

3). Hafalan surah-surah pendek mulai dari surah Annas s/d AdDhuha.

4). Ilmu Tajwid. 
5). Bacaan shalat fardhu dan praktek

6). Bacaan do'a harian.

b. Pengkaderan Remaja Tentang Pendidikan Agama dan Organisasi.

Melihat jumlah pemuda di Masjid Agung Bangil yang begitu banyak saat, kita perlu menyiapkan dan menjadikan masjid sebagai wadah bagi pembinaab pendidikan bagi para pemuda, karena peran pemuda di masjid dirasa sangat penting, karena kaum remaja dan pemuda adalah generasi harapan, menjadi tulang punggung masjid dan menaruh harapan besar bagi kesejahteraan masjid di masa sekarang maupun di masa yang akan datang. Oleh karena itu, sebagai sesepuh sekaligus orang tua yang akan digantikan perannya oleh kaum muda, kita harus membekali kaum muda dengan pengalaman atau pendidikan dan berpartisipasi dalam kegiatan yang diselenggarakan oleh pihak masjid. Sehingga suatu hari mereka dapat terus mengelola roda kepengurusan yang lebih baik.

c. Menyelenggarakan Pengajian (Majelis Ta'lim).

Masjid Agung Bangil mengagendakan pengajian harian Majelis Ta'lim untuk umum. Bapak-bapak dan anak-anak kecil dapat berpartisipasi. Tujuannya untuk memupuk dan meningkatkan keimanan dan amal 
shaleh jamaah, agar umat Islam dapat meningkatkan keimanan dan ketaqwaan kepada Allah. Adapun ruang lingkup kegiatannya adalah:

1) Meningkatkan keimanan dan menghilangkan buta huruf agama dan buta huruf Al-Qur'an.

2) Meningkatkan akhlak

3) Mengaplikasikan ajaran Islam dalam bidang kemasyarakatan, pendidikan, kebudayaan dan kesehatan.

4) Menjalani kehidupan yang lebih produktif

5) Mendorong siswa untuk terus belajar dalam memecahkan masalah sehari-hari, seperti membaca, dan memperluas pengetahuan berpikirnya.

d. Tabligh Akbar

Tabligh akbar merupakan rangkaian kegiatan yang dilaksanakan dalam setiap acara Perayaan Hari Besar Islam, karena kegiatan Tabligh Akbar pada hakikatnya merupakan konsep menjalin komunikasi dalam rangka menjalin silaturahmi antar umat beriman. Oleh karena itu, Tabligh Akbar sebenarnya membangun persatuan masyarakat dengan memperkenalkan ulama-ulama terkenal yang dapat mencairkan 
suasana kerinduan dan persatuan warga untuk melakukan pertukaran intelektual, spiritual dan sosial antara lain, sehingga tujuan keagamaan dan sosial dapat terwujud dengan benar.

\section{Kesimpulan}

Masjid Agung Bangil memanfaatkan fungsi masjid dengan baik, seperti pada fungsi masjid di zaman Nabi Muhammad SAW, yang menjadikan masjid sebagai pusat pembinaan sosial dan pendidikan kepada para jamaah, serta memberikan pelayanan informasi dan komunikasi teraktual bagi masyarakat. Adapun nilai pelayanan sosial tercermin dalam beberapa aspek, antara lain memahami ciri khas pelayanan yang diberikan dan nilai persatuan masyarakat, kepedulian dan simpati, kepercayaan dan organisasi spiritual bagi yang kurang mampu. Dengan mengikutsertakan segala ide, membuahkan hasil dalam melakukan kegiatan ibadah dan kegiatan sosial, mendahulukan kepentingan para jamaah, dan mengemban misi dan tanggung jawab pelaksana melalui visi dan misi yang diimplementasikan. 


\section{Daftar Pustaka}

Al Munawar, Said Agil Husein. Sambutan Menteri Agama Republik Indonesia, Dalam Buku Pedoman Manajemen Masjid.

Hajma, Tajuddin. "Manajemen Kemasjidan". Makalah yang disajikan selama proses perkuliahan berlangsung di Universitas Islam Negeri Alauddin Makassar, Kampus II Samata-Gowa. 2016.

Hasibuan, Malayu. Manajemen: Dasar, Pengertian, dan Masalah, Ed. Revisi, Cet. 6 Jakarta: Bumi Aksara. 2007.

Iwanullah, Ade Ridwan \& Herdiana, Dedi. "Optimalisasi Pemberdayaan Masyarakat Berbasis Masjid", Jurnal Ilmu Dakwah Volume 12 Nomor 1. 2018.

Muhidin. Pengantar Kesejahteraan Sosial. Bandung: Sekolah Tinggi Kesejahteraan Sosial. 1992.

Rohman dkk. "Program Pemberdayaan Masyarakat Berbasis Masjid", Journal Lifelog Learning Vol. 3 No. 2. 2020.

Roqib, Moh. Menggugat Fungsi Edukasi Masjid, Yogyakarta: Grafindo Litera Media. 2005.

Yani, A. dkk. Panduan Mengelola Masjid, Jakarta: Pustaka Intermasa. 2007. 